\title{
EDITORIAL
}

\section{MEJOR (SERVICIO) SIEMPRE ES MÁS (SALUD)}

\author{
Vicente Ortún Rubio \\ Director Centro de Investigación en Economía y Salud. Departamento de Economía y Empresa. Universidad Pompeu \\ Fabra. Barcelona
}

Desde que hace cinco años Vicky Zunzunegui abordara una pregunta parecida en esta sección ${ }^{1}$, distintas contribuciones a la Revista han tratado el tema según muestra el índice por materias de su excelente página web. Afortunadamente, el editorial brota espontáneo pues la petición del mismo llega tras la presentación en Davos del libro del top-gurú mundial Porter sobre reformas de sistemas sanitarios (ventas millonarias aseguradas) y el mucho más interesante duelo reciente en OK Health Affairs entre David Cutler $^{2}$, conferenciante inaugural de las XXV Jornadas de la Asociación de Economía de la Salud (Barcelona, 2005), y Elliott Fischer $^{3}$, conferenciante inaugural de las XXIV Jornadas AES (El Escorial, 2004), cuyos entresijos servirán, en lo que sigue, para situar los dos artículos de este número de la revista que me piden enmarcar.

\section{Del buen empleo de la calderilla}

En promedio, la atención sanitaria produce más beneficios, en cantidad y calidad de vida, que costes pero, al mismo tiempo, más no siempre es mejor sino que, con frecuencia, suele ser peor. Como sociedades gastamos ingentes sumas desarrollando nueva tecnología (900 millones de dólares, por ejemplo, cada medicamento) y sólo calderilla hallando formas de utilizar mejor la tec- nología de la que ya disponemos. Sin embargo, para conseguir asistencia de calidad basta aplicar lo que ya se sabe y recordar las constataciones básicas que venimos repitiendo hace años:

1. Los sistemas sanitarios funcionarán cuando los profesionales sanitarios que asignan los recursos tengan la información y los incentivos convenientes para tomar decisiones clínicas coste-efectivas.

2. La auténtica gestión sanitaria y la auténtica gestión clínica pasan por reducir el 'abismo' entre lo que puede lograrse, con la tecnología y los recursos disponibles, y lo que realmente estamos obteniendo.

3. No pagues por A si quieres obtener B. Si pretendes calidad paga por ella. Cuestión de incentivos entre dos actores: el usuario y el profesional. Algo se puede hacer sobre el primero, mucho sobre el segundo.

El mismo año que el editorial antes citado $^{1}$, la publicación del Informe del Instituto de Medicina de EE.UU. ${ }^{4}$ confirmó que entre la asistencia sanitaria que tenemos y la que podríamos tener no sólo existe un trecho sino un abismo. No falta dinero ni tecnología 
ni conocimiento. Más no siempre es mejor: Cómo se gasta (¡la buena Medicina!) resulta más relevante que cuánto se gasta. Preocuparse por lo que importa -la efectividad, reducir el abismo en calidad-supone incomprensiones, luce poco y consigue escasa financiación. Pese a todo, la motivación intrínseca funciona y encontramos en nuestra literatura publicaciones que informan sobre experiencias validadas de mejora, incluso revistas de publicaciones secundarias -por ejemplo Gestión Clínica y Sanitaria- empeñadas en la cruzada. Como esquema inspirador sirva el trabajo de Salvador Peiró acerca de la reducción de la brecha entre eficacia y efectividad en el abordaje en España ${ }^{5}$ del infarto agudo de miocardio.

El artículo del profesor Francisco de Asís Acurcio y sus colaboradores ${ }^{6}$ en este número de la revista, se sitúa asimismo en la línea de investigación que trata de contribuir a desplazar las prácticas observadas -en este caso el tratamiento de sujetos infectados por VIH en Belo Horizonte- hacia la frontera de posibilidades de producción, horizonte lejano que puede alcanzarse si todo funciona bien. Se trata de otro ejemplo del buen empleo de la calderilla que la investigación sobre servicios sanitarios exige y que puede ayudar al mejor uso de la tecnología ya disponible.

\section{Del pagar por 'ser' al pagar por resultado pasando por el pagar por 'hacer'}

En los primeros conciertos del extinguido Instituto Nacional de Previsión con hospitales ajenos a la Seguridad Social se partía de la estructura de éstos para pactar las tarifas. Desde 1978 el también desaparecido Instituto Nacional de la Salud utilizó como criterio fundamental de pago lo que el hospital 'era': grado de especialización de sus servicios, dotación de medios diagnósticos y terapéuticos, calificación de las plantillas, etc. Se desarrolló incluso una parrilla de categorías -desde básico rural a urbano con mucha superespecialización- en la que cualquier centro hospitalario encajaba. Se pagaba pues por 'ser', con la hipótesis implícita, si se quiere, de que una mayor complejidad de la oferta iba asociada a una mayor diversidad y gravedad de los enfermos atendidos, hipótesis que obviamente era rechazable en bastantes ocasiones.

Parecía más sensato que los centros sanitarios fueran compensados en función de lo que 'hacían' pero -como sabemos- no es lo mismo medir kilowatios o toneladas de acero que estancias o visitas. Fueron los sistemas de ajuste de riesgo los que permitieron clasificar a los pacientes en grupos de isoconsumo de recursos. Si no sabe medirse lo que 'hacen' los centros no pueden establecerse comparaciones ni asignarse los recursos (presupuestos, contratos...) a quienes mejor lo hagan. Efectivamente, la carencia de una medida del producto (aunque fuera intermedio) era un problema sanitario como lo era -y continúa siéndolo- en los sistemas en educación, justicia, defensa, policía, o asuntos exteriores. Tampoco algunas actividades de las organizaciones que producen directamente para el mercado se escapan de esta dificultad: relaciones públicas, recursos humanos o planificación estratégica; en ocasiones han de recurrir a una modalidad de benchmarking conocida como método Bruegel o 'ciegos conduciendo a ciegos'.

Los Grupos Relacionados con el Diagnóstico (GRD) de Fetter, implantados en EE.UU. al inicio del año fiscal de 1984, permitieron aproximar mejor la medida de una parte del producto intermedio hospitalario (lo que se «hace»), además de ilustrar una rápida transición de la investigación universitaria sobre servicios sanitarios a la aplicación práctica y su rápida difusión. En España, en 1987, el Consejo Interterritorial del Ministerio de Sanidad y Consumo aprobó establecer un Conjunto Mínimo Básico de Datos (CMBD) al alta hospitalaria, de acuerdo con los aceptados tanto por el Comité Nacional de Estadísticas Vitales y de Salud 
de EE.UU., como por la Comisión de las Comunidades Europeas sobre el conjunto mínimo básico de datos europeo, lo cual facilitó la extensión de los GRD.

Los Grupos Clínicos Ajustados (GCA) también vinieron de EE.UU, esta vez de Johns Hopkins, con el ánimo de medir el producto intermedio en atención ambulatoria, y fueron objeto de tempranas validaciones en Andalucía y Cataluña, fundamentalmente. Sin embargo, España continúa sin un CMBD en Atención Primaria. El artículo de Antoni Sicras y colaboradores ${ }^{7}$ obtiene pesos relativos del coste de la asistencia a través de los GCA con la vista puesta en la generalización del pago capitativo con base territorial que se está desarrollando en Cataluña. Además de los interesantes resultados, los autores insisten en el imprescindible combate contra esa gran infección nosocomial originada por el virus no computer.

Tres sistemas de ajuste de riesgo basados en el diagnóstico pueden ser útiles tanto para un pago capitativo de base territorial como para identificar pacientes tributarios de gestión de casos, seguir el estado de salud de las poblaciones y planificar/evaluar los servicios sanitarios: el mencionado GCA, el de los Clinical Risk Groups (GRG) de 3M y el de las Hierarchical Co-existing Conditions (HCC) de DxCG, citados por el orden de atención que hasta ahora han recibido en España. Antes de optar sensatamente por uno de los tres, el trabajo pendiente por acometer puede verse, por ejemplo, en un reciente documento de la Fundación Canadiense de Investigación sobre Servicios Sanitarios ${ }^{8}$ que ha orientado la opción de varias provincias hacia los ACG.

'Hacer' no obstante sigue implicando visitas, exploraciones, intervenciones, etc., algunas de las cuales -como las vinculadas con el internamiento hospitalario- podemos aproximar aceptablemente y otras -como la consulta ambulatoria de los hospitales con- tada con los dedos y sin ajustar- no tanto. En cualquier caso, ha sido posible efectuar una transición paulatina desde premiar el 'ser' a compensar por 'hacer', manteniendo donde está indicado -cámara hiperbárica, servicio de urgencias rural-el pago por 'ser' (en este tipo de servicios cuanto menos 'hagan' mejor).

Cuando falta todavía mucho para llegar a medidas satisfactorias de actividad, curiosamente sabemos que ese no es el destino. En una sociedad de enfermos crónicos (diabéticos, EPOC, insuficientes cardíacos...), un mayor frenesí asistencial no suele ser indicio de mejor calidad sino todo lo contrario: Cuanto más (ingresos no programados, comas...) peor. ¿Por qué financiamos públicamente los servicios sanitarios? Por su impacto en la salud. Pensemos, pues, en pagar por él. De acuerdo, muchas son las variables que influyen en el estado de salud y resulta muy difícil establecer el porcentaje atribuible a la intervención sanitaria. Remontémonos un poco en el tiempo, hasta antes de nacer; si supiéramos que seremos diabéticos o que tendremos un cáncer digestivo, ¿en qué país del mundo nos gustaría vivir? En el que mejor controle la diabetes -medible a través de la hemoglobina glicosilada- o en el que tuviera mayor supervivencia tras cáncer -aproximable, por ejemplo, por el porcentaje de cánceres digestivos diagnosticados en Urgencias Hospitalarias. Algo puede, pues, decirse ya sobre los resultados que realmente importan a los ciudadanos.

El necesario avance hacia medidas de resultado de la atención sanitaria contribuirá a reducir la brecha entre eficacia y efectividad y a obtener una base de evaluación del comportamiento sobre la que incentivar la calidad de los proveedores y la elección informada de los usuarios. Todo con un coste mundial de investigación en servicios sanitarios muy inferior al de desarrollar un nuevo medicamento. Más no siempre es mejor, pero mejor (servicio) siempre es más (salud). 


\section{BIBLIOGRAFÍA}

1. Zunzunegui M. ¿Más servicios o mejores servicios? Calidad y eficiencia en los servicios hospitalarios para las personas mayores. Rev Esp Salud Pública. 2001; 75: 181-182.

2. Cutler D. Making sense of medical technology, Health Affairs [edición electrónica]. 2006 [publicado 7 febrero]. Disponible en: http://content.healthaffairs.org/cgi/reprint/hlthaff.25.w48v1

3. Skinner J, Staiger D, Fisher E. Is technological change in medicine always worth it? The case of acute myocardial infarction. Health Affairs [edición electrónica].2006 [publicado 7 febrero]. Disponible en: http://content.healthaffairs.org/cgi/reprint/hlthaff.2 5.w34v1

4. Institute of Medicine. Crossing the Quality Chasm: A New Health System for the 21st century. Washington: National Academy Press; 2001.
5. Peiró S. De la gestión de lo complementario a la gestión integral de la atención a la salud. En Ortún V (dir): Gestión Clínica y Sanitaria. Barcelona: Masson; 2003. p 17-87.

6. Acurcio FA, Puig-Junoy J, Bonolo PF, Ceccato MGB, Guimarães MDC. Análisis coste-efectividad de la adhesión inicial a la terapia antirretroviral entre individuos afectados por el VIH en Belo Horizonte, Brasil. Rev Esp Salud Pública. 2006; 80: 41-54.

7. Sicras-Mainar A, Serrat-Tarrés J, Navarro-Artieda R, Llopart López JR. Posibilidades de los grupos clínicos ajustados en el ajuste de riesgos de pago caritativo. Rev Esp Salud Pública. 2006; 80: 55-65.

8. Berlinguet M, Preyra C, Dean S. Comparing the value of three main diagnostic-based risk-adjustment systems. Canadian Health Services Research Foundation; 2005. Accesible en: http://www. chsrf.ca/final_research/ogc/pdf/berlinguet_final.pdf 